\title{
An Eco-Friendly Approach to Low-Temperature and Near-Neutral Bleaching of Cotton Knitted Fabrics Using Glycerol Triacetate as an Activator
}

\author{
Yu Zhou \\ Jiangnan University \\ Guolin Zheng \\ Jiangnan University \\ Jinfang Zhang \\ Man Zhou \\ Jiangnan University \\ Yuanyuan Yu \\ Jiangnan University \\ Ping Wang \\ Jiangnan University
}

Zhejiang HAOYU Technology Co. Ltd.

Qiang Wang ( $\square$ qiang_wang@163.com )

Jiangnan University https://orcid.org/0000-0002-8461-6552

\section{Research Article}

Keywords: Cotton, Low temperature bleaching, Glycerol triacetate, Peracetic acid

Posted Date: April 19th, 2021

DOl: https://doi.org/10.21203/rs.3.rs-411525/v1

License: (9) This work is licensed under a Creative Commons Attribution 4.0 International License.

Read Full License 


\section{Abstract}

Near-neutral bleaching of cotton fabrics at low temperature is of great importance for saving energy and ecological friendliness in textile industry. In this work, glycerol triacetate (GT) was investigated as an activator of hydrogen peroxide $\left(\mathrm{H}_{2} \mathrm{O}_{2}\right)$ for low temperature bleaching of cotton knitted fabrics, and satisfactory whiteness was obtained. The bleaching properties of $\mathrm{H}_{2} \mathrm{O}_{2} / \mathrm{GT}$ system for cotton was assessed by the $\mathrm{CIE}$ whiteness index, $\mathrm{H}_{2} \mathrm{O}_{2}$ decomposition rate, concentration of generated peracetic acid (PAA) and bursting strength. Possible factors affecting the performance of $\mathrm{H}_{2} \mathrm{O}_{2}$ /GT bleaching system were discussed in detail. Adding only $10 \mathrm{mmol} / \mathrm{L}$ GT to the hydrogen peroxide solution $(60 \mathrm{mmol} / \mathrm{L})$ to bleach cotton knitted fabrics at $60{ }^{\circ} \mathrm{C}$ for 60 min, the WI was significantly increased from 52.09 to 68.92 . By using benzenepentacarboxylic acid as a fluorescent probe for hydroxyl radical ( $\mathrm{HO} \cdot)$ detection, it was found that GT could clearly promote $\mathrm{HO}$ - generation and the concentration of $\mathrm{HO}$ - closely related to the WI of cotton fabric. Furthermore, the bleaching mechanism of $\mathrm{H}_{2} \mathrm{O}_{2} / \mathrm{GT}$ system to cotton was proposed by exploring the relationship between $\mathrm{WI}$ and $\mathrm{HO}$ - concentration. As a bleach activator, GT has more economical benefits and better solubility in water than that of TAED. The $\mathrm{H}_{2} \mathrm{O}_{2}$ /GT system may provide a cost-effective and environmentally friendly approach as alternative to conventional alkaline hightemperature bleaching of cotton.

\section{Introduction}

Cotton fiber is one of the most popular materials used in the textile industry for its excellent properties such as high moisture absorption, comfortable wearability and easy dyeing. However, raw cotton contains natural yellowish impurities which detract from the inherent white appearance of cotton cellulose (Wakelyn et al. 2007). Moreover, the epidermis of cotton fiber is composed of cotton wax, pectin and fat, which hinders the subsequent dyeing and finishing. Hence, prior to dyeing and other finishing processes, pretreatment of cotton fabric is essential to remove these impurities and whiten cotton fabric. Bleaching of cotton with hydrogen peroxide $\left(\mathrm{H}_{2} \mathrm{O}_{2}\right)$ is the most widely used method in the textile industry due to its low cost and environmental friendliness (Zeronian and Inglesby 1995). However, traditional $\mathrm{H}_{2} \mathrm{O}_{2}$ bleaching process is usually carried out under nearly boiling temperature $\left(>95^{\circ} \mathrm{C}\right)$ and alkaline condition ( $\mathrm{pH} 11-12)$ to obtain ideal properties, which consumes large amounts of energy, contributes to strongly alkaline effluent and causes severe damage to cotton fibers. In recent decades, great efforts have been made to lower bleaching temperature and shorten duration by incorporating various bleach activators and catalysts into $\mathrm{H}_{2} \mathrm{O}_{2}$ aqueous solution (Abdel-Halim and Al-Deyab 2013; Hashem et al. 2010; Hebeish et al. 2009). Besides, some auxiliary methods are effective for cotton fabric pretreatment, such as plasma (Sun and Stylios GK 2004) radiation (Bashar et al. 2015) and ultrasonic techniques (Li et al. 2020).

Utilization of activators allows the bleaching process to carry out under mild conditions and significantly reduce the bleaching temperature. Some studies have found that the low temperature bleaching system

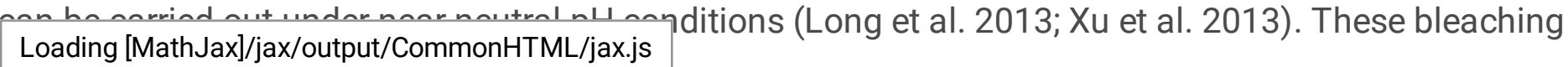


activators mainly include tetraacetylethylenediamine (TAED) (Hebeish et al. 2009; Long et al. 2013; Shao et al. 2010; Xu et al. 2013), N-[4-(triethylammoniomethyl)-benzoyl]-caprolactam chloride (TBCC) and other lactam-based cationic bleach activators (Chen et al. 2016; Lee et al. 2010; Lim et al. 2006; Luo et al. 2019; Xu et al. 2015). Other activators like sodium nonanoyl oxybenzene sulphonate (NOBS) (Cai et al. 2001), amino nitriles as well as the derivatives of the cyanamide (Neal JM 1998), thiourea (Abdel-Halim and AlDeyab 2013), pentaacetyl glucose (PAG) (Liu et al. 2017) and tetraacetylhydrazine (TH) (Liu et al. 2018) are also effective low-temperature bleaching activators. Studies showed that bleach activators could react with $\mathrm{HOO}^{-}$in alkaline solution via the perhydrolysis reaction to form peroxyacid, which is recognized as a more kinetically reactive oxidant and has higher oxidation potential and stronger oxidizing properties compared to $\mathrm{H}_{2} \mathrm{O}_{2}$ and enables cotton to be bleached at low temperature (Bianchetti et al. 2015; Hofmann et al. 1992). The effects of various bleaching factors in the activated peroxide systems on whiteness index (WI) of bleached cotton fabrics were systematically discussed (Fei et al. 2015). Nevertheless, these bleaching activators have certain defects in different aspects, such as poor water solubility of TAED, unpleasant odor when using NOBS bleaching, etc. Cost effectiveness, environmental concerns and energy consumption are the major considerations for the textile industry, which have promoted the research of new effective activators to meet the ever-growing industrial demands.

Glycerol triacetate is a common and cheap carboxylic acid ester and has good biocompatibility, nontoxicity and easy access. Compared with other bleach activators, GT does not require complex synthesis process and is extremely low in cost. In our present work, GT was investigated as an activator of $\mathrm{H}_{2} \mathrm{O}_{2}$ to bleach gray knitted cotton fabric at low temperature. The whiteness of bleached cotton knitted fabrics as function of GT dosage, $\mathrm{pH}$, bleaching temperature and duration were assessed when $\mathrm{H}_{2} \mathrm{O}_{2}$ /GT bleaching system was utilized. The properties of cotton fabrics bleached by $\mathrm{H}_{2} \mathrm{O}_{2}$ using GT and TAED as activators were compared in terms of the degree of whiteness, bursting strength and $\mathrm{H}_{2} \mathrm{O}_{2}$ decomposition rate. In addition, $\mathrm{HO}$. concentration and peroxyacetic acid (PAA) concentration were monitored to prove the bleach performance of this system. Finally, the bleaching mechanism of $\mathrm{H}_{2} \mathrm{O}_{2}$ /GT system was evidencebased proposed.

\section{Experimental}

\subsection{Materials}

Gray cotton knitted fabric $\left(150 \mathrm{~g} / \mathrm{m}^{2}\right)$ was supplied by Jiangsu Lianfa Textile Co. Ltd. China. The WI of the gray cotton knitted fabric is -3.31. DM 1364 was used as a scouring agent and purchased from Demei Chemicals Co., Ltd. China. Benzenepentacarboxylic acid (BA, 99\%) and Diacetin (45-50\%) were purchased from Aladdin Biochemical Technology (Shanghai) Co., Ltd. China. Monoacetin ( $\geq 45 \%$ ) was purchased from Runfeng Petrochemical (Nantong) Co., Ltd. China. Glycerol triacetate ester (GT, 98.5\%), hydrogen peroxide $\left(\mathrm{H}_{2} \mathrm{O}_{2}, 30 \mathrm{wt} \%\right)$, sodium bicarbonate (99\%), sodium carbonate $(99.8 \%)$, sodium 
$\left(\mathrm{Na}_{4} \mathrm{P}_{2} \mathrm{O}_{7}, 99 \%\right)$, potassium permanganate $(99.5 \%)$, sodium thiosulfate $(99.5 \%)$, sulfuric acid $(96 \%)$, manganese sulfate (99\%), ammonium molybdate tetrahydrate (99\%), potassium iodide (99\%) and soluble starch (99\%) were purchased from Sinopharm Chemical Reagent Co., Ltd., China. Deionized water was used throughout except the washing process of fabric.

\subsection{Methods}

\subsubsection{Scouring of cotton fabric}

The scouring processes were carried out in a reciprocating shaker bath and performed at $95{ }^{\circ} \mathrm{C}$ for 60 min with a liquor ratio of 20:1. Each scouring solution contained DM $1364(1 \mathrm{~g} / \mathrm{L})$ and $\mathrm{NaOH}$. $(8 \mathrm{~g} / \mathrm{L})$. After the reactions, the samples were removed from reaction solutions and rinsed in hot and cool water. Then the samples were dried under ambient temperature.

\subsubsection{Bleaching of cotton fabric}

Scoured cotton fabric samples were immersed in $100 \mathrm{~mL}$ bleaching solutions which contained nonionic surfactant DX-100 (1 g/L), 30\% $\mathrm{H}_{2} \mathrm{O}_{2}(60 \mathrm{mmol} / \mathrm{L})$ and sodium pyrophosphate $(2 \mathrm{~g} / \mathrm{L})$. GT was used as bleach activators in the above solutions according to specific conditions. The bleaching processes was carried out in a reciprocating shaker bath and maintained at different $\mathrm{pH}$ and temperature for 60 minutes with a liquor ratio of 20:1. After the reactions, the fabrics were rinsed thoroughly in copious amounts of tap water. Finally, the bleach cotton fabric samples were dried under ambient temperature.

\subsubsection{Detection of hydroxyl radical}

Benzenepentacarboxylic acid (BA) was used as a fluorescent probe to capture $\mathrm{HO}$ - according to previous studies ( $\mathrm{Si}$ et al. 2014a, b). $\mathrm{H}_{2} \mathrm{O}_{2}(220 \mu \mathrm{mol} / \mathrm{L})$ and $\mathrm{GT}(400 \mu \mathrm{mol} / \mathrm{L})$ were added in a reaction solution containing BA $(400 \mu \mathrm{mol} / \mathrm{L})$. And the $\mathrm{pH}$ value of the solution was adjusted to 10 by Sodium hydroxide. The reaction was kept for $60 \mathrm{~min}$ at $60^{\circ} \mathrm{C}$ and the solution was promptly cooled by water to ambient temperature. Fabric and surfactant were not involved to eliminate their impact on the accuracy of measurement. A certain amount of working solution was placed in the four-pass optical quartz cuvette, and the fluorescence intensity was measured at maximum excitation wavelength $(311 \mathrm{~nm})$ or maximum emission wavelength $(435 \mathrm{~nm})$ to characterize the concentration of $\mathrm{HO}$. The fluorescence intensity was measured on Hitachi F-7000 spectrophotofluorometer with Ex/Em slit widths of $5 \mathrm{~nm}$ using an excitation voltage of $400 \mathrm{~V}$.

\subsubsection{Scavenging of $\mathrm{HO}$.}

DMSO (1-5 g/L) was used to scavenge $\mathrm{HO}$. during bleaching processes to clarify the effect of $\mathrm{HO} \cdot$ on WI in $\mathrm{H}_{2} \mathrm{O}_{2}$ /GT system ( $\mathrm{Si}$ et al. 2014a), and the fabrics were treated with $25 \mathrm{mmol} / \mathrm{L} \mathrm{GT}$ at $60^{\circ} \mathrm{C}$, other reaction regents and test conditions are the same as that used in bleaching of fabric.

\subsection{Measurement}


CIE Whiteness Index (WI) of cotton fabric samples was measured by Datacolor 850 color matching instrument (Datacolor International, USA) according to ISO 105-J02: 1997 standard. Each samples Each sample was measured for four times in different positions to give an average value. The average value of three pieces of cotton fabric recorded.

Bursting strength of cotton fabric samples was determined by H10KS fabric strength tester according to ISO 13938-1:1999 standard.

$\mathrm{H}_{2} \mathrm{O}_{2}$ decomposition rate was measured by consuming a certain concentration of potassium permanganate solution and calculated by the following Eq. 1.

$$
\mathrm{H}_{2} \mathrm{O}_{2} \text { decomposition rate }=\frac{V_{0}-V_{1}}{V_{0}}
$$

where $\mathrm{V}_{0}$ is the volume of potassium permanganate solution consumed by titration of $5 \mathrm{~mL}$ bleaching liquid before reaction and $V_{1}$ is the volume of potassium permanganate solution consumed by titration of $5 \mathrm{~mL}$ bleaching liquid after reaction.

The amount of peracetic acid (PAA) was measured by titration method according to GB/T $19108-2003$. $\mathrm{H}_{2} \mathrm{O}_{2}$ in bleaching effluent liquor was titrated with a certain concentration of potassium permanganate solution, and then the concentration of PAA was determined by indirect iodometry and calculated by the following Eq. 2

$$
\omega(\mathrm{PAA})=\frac{V * C * M}{m}
$$

where $\mathrm{V}$ is the volume value of the titration solution consumed by sodium thiosulfate, $\mathrm{c}$ is the concentration value of sodium thiosulfate, $\mathrm{M}$ is the value of the molar mass of peracetic acid equivalent to $1 \mathrm{ml}$ sodium thiosulfate titration solution and $\mathrm{m}$ is the volume value of bleaching effluent.

\section{Results And Discussion}

\subsection{Performance of cotton knitted fabrics bleached in $\mathrm{H}_{2} \mathrm{O}_{2}$ /GT system}

\subsubsection{Effect of $\mathrm{pH}$}

The effect of $\mathrm{pH}$ values of $\mathrm{H}_{2} \mathrm{O}_{2} / \mathrm{GT}$ system on the performance of bleached cotton fabrics was investigated in terms of WI, as displayed in Fig. 1. The WI of cotton fabrics bleached by $\mathrm{H}_{2} \mathrm{O}_{2}$ with and without $\mathrm{GT}$ as the activator showed different trends. As the $\mathrm{pH}$ value of bleaching system increased, the WI of cotton fabric bleached by $\mathrm{H}_{2} \mathrm{O}_{2}$ continuously rose from 37.73 to 60.17 . However, in $\mathrm{H}_{2} \mathrm{O}_{2} / \mathrm{GT}$ 
system, the $\mathrm{WI}$ rose first and then fell, and the optimal level of $\mathrm{WI}$ were obtained at $\mathrm{pH} 8-9$. Therefore, the $\mathrm{pH}$ value should be selected at 8-9 in $\mathrm{H}_{2} \mathrm{O}_{2}$ /GT bleaching system.

Bimolecular decomposition of peracid had been recognized as the main reason to cause the loss of bleaching performance under stronger alkali conditions (Xu et al. 2013), and the experimental results were consistent with it. From this point of view, it was more conducive for $\mathrm{H}_{2} \mathrm{O}_{2}$ /GT system to bleach cotton fabric under weak alkaline conditions. Sodium bicarbonate $\left(\mathrm{NaHCO}_{3}\right)$ could promote the generation of $\mathrm{HOO}^{-}$from $\mathrm{H}_{2} \mathrm{O}_{2}$ and maintain $\mathrm{pH}$ in a near-neutral range before and after bleaching, which could enhance the perhydrolysis of GT to form peracetic acid for improving the WI of cotton fabric and inhibit two types of ineffective decomposition of PAA.

\subsubsection{Effect of GT dosage}

The effect of GT dosage on the performance of $\mathrm{H}_{2} \mathrm{O}_{2}$ /GT system was investigated by $\mathrm{Wl}_{1} \mathrm{H}_{2} \mathrm{O}_{2}$ decomposition rate and PAA concentration. As shown in Fig. 2, with the GT dosage increasing from 0 to $25 \mathrm{mmol} / \mathrm{L}$ at $60{ }^{\circ} \mathrm{C}$, the Wl of cotton knitted fabrics rose from 52.09 to 72.29 and the $\mathrm{pH}$ value of the bleached solution declined from 9.06 to 7.55 . The WI nearly leveled off and the $\mathrm{pH}$ value declined from 7.55 to 7.22 when the GT concentration further increased to $60 \mathrm{mmol} / \mathrm{L}$ (Fig. 2a). In addition, $\mathrm{H}_{2} \mathrm{O}_{2}$ decomposition rate ascended from 29.3-52\% and PAA concentration increased from 4.35 to 12.37 $\mathrm{mmol} / \mathrm{L}$ with the GT concentration increasing from 10 to $60 \mathrm{mmol} / \mathrm{L}$ (Fig. 2b). Therefore, GT dosage should be controlled at a suitable level in $\mathrm{H}_{2} \mathrm{O}_{2}$ / GT cotton bleaching system since higher GT concentration could not bring an obvious increase in the WI.

The results revealed that the use of GT could activate $\mathrm{H}_{2} \mathrm{O}_{2}$ and promote the decomposition of $\mathrm{H}_{2} \mathrm{O}_{2}$ to produce PAA with stronger oxidation ability. This can be explained that $\mathrm{H}_{2} \mathrm{O}_{2}$ could produce $\mathrm{HOO}^{-}$at alkaline condition, and then $\mathrm{HOO}^{-}$attacked the acyl of GT to generate PAA in situ. Finally, impurities were removed from cotton fabric efficiently at lower temperature due to the stronger oxidability of PAA and active substances decomposed by PAA. Simultaneously, excessive GT could lead to the decrease in pH value of bleaching solution owing to the fact that the hydrolysis of GT and the decomposition of PAA could produce acetic acid.

\subsubsection{Effect of reaction temperature}

Bleaching temperature is one of the most important factors affecting the WI of cotton fabrics in $\mathrm{H}_{2} \mathrm{O}_{2} / \mathrm{GT}$ system. As is shown in Fig. 3 , the performance of $\mathrm{H}_{2} \mathrm{O}_{2}$ /GT system and $\mathrm{H}_{2} \mathrm{O}_{2}$ system on bleaching of cotton knitted fabrics was investigated from 30 to $80^{\circ} \mathrm{C}$. The WI of cotton fabrics bleached by $\mathrm{H}_{2} \mathrm{O}_{2} / \mathrm{GT}$ system greatly increased from 49.29 to 69.03 as the temperature rising from 30 to $50^{\circ} \mathrm{C}$, which means that cotton fabric bleaching could be conducted at lower temperature of $50^{\circ} \mathrm{C}$ in this system, and the WI could be observably improved. Afterwards, the WI increased mildly when temperature rose from 50 to

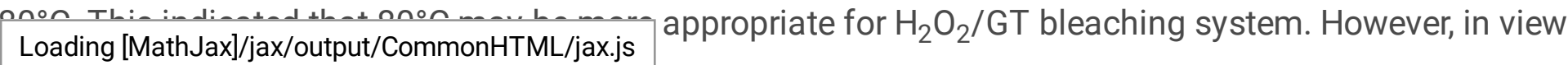


of the performance of the bleached cotton fabrics and energy saving, the temperature was set to $60^{\circ} \mathrm{C}$ in $\mathrm{H}_{2} \mathrm{O}_{2} / \mathrm{GT}$ bleaching system since the WI would not increase clearly with increasing temperature to $80^{\circ} \mathrm{C}$.

These results demonstrated that the rate of perhydrolysis of GT and decomposition of PAA during bleaching could be accelerated due to the accelerated rate of $\mathrm{H}_{2} \mathrm{O}_{2}$ decomposition by increasing temperature. Consequently, the selection of bleaching temperature in $\mathrm{H}_{2} \mathrm{O}_{2}$ /GT system should balance high efficiency and energy saving.

\subsubsection{Effect of $\mathrm{Na}_{4} \mathrm{P}_{2} \mathrm{O}_{7}$ concentration}

$\mathrm{Na}_{4} \mathrm{P}_{2} \mathrm{O}_{7}$ was preferably selected as the stabilizer in $\mathrm{H}_{2} \mathrm{O}_{2}$ /GT bleaching system to prevent the ineffective decomposition of $\mathrm{H}_{2} \mathrm{O}_{2}$. The presence of $\mathrm{Na}_{4} \mathrm{P}_{2} \mathrm{O}_{7}$ exerted a considerable influence on WI of cotton fabric as shown in Fig. 4. The WI of cotton fabric was greatly increased from 50.15 to 70.64 when $\mathrm{Na}_{4} \mathrm{P}_{2} \mathrm{O}_{7}$ was added from 0 to $1 \mathrm{~g} / \mathrm{L}$. Thereafter, the WI stayed relatively constant with $\mathrm{Na}_{4} \mathrm{P}_{2} \mathrm{O}_{7}$ increasing from 1 to $5 \mathrm{~g} / \mathrm{L}$. Hence, adding a small amount of $\mathrm{Na}_{4} \mathrm{P}_{2} \mathrm{O}_{7}$ could obviously improve the WI of cotton fabric, while the WI changed less by $\mathrm{Na}_{4} \mathrm{P}_{2} \mathrm{O}_{7}$ concentration.

$\mathrm{Na}_{4} \mathrm{P}_{2} \mathrm{O}_{7}$ is an inorganic salt which has the functions of buffering, chelating and softening water, which can comprehensively exert the above functions when used as $\mathrm{H}_{2} \mathrm{O}_{2}$ bleaching stabilizer. By effectively chelating iron, copper, manganese and other heavy metal ions, thus avoiding severe damage to cotton knitted fabrics caused by catalytic decomposition of hydrogen peroxide.

\subsubsection{Effect of bleaching time}

As shown in Fig. 5 , the duration of bleaching exhibited a positive effect on WI of cotton fabric. The WI of cotton fabric in $\mathrm{H}_{2} \mathrm{O}_{2}$ /GT system continuously ascended with the prolongation of bleaching time. After bleaching for $30 \mathrm{~min}$, the WI of scoured cotton knitted fabrics strikingly increased from 24.47 to 66.35. With further extension of bleaching duration, the WI of cotton fabrics tended to level off. This can be explained by the fact that at the early stage of bleaching, $\mathrm{H}_{2} \mathrm{O}_{2}$ decomposed faster under weak alkaline conditions, and the PAA generated by the perhydrolysis reaction with GT was consumed quickly. Therefore, as the $\mathrm{pH}$ value of the reaction system continued to fall in the later stage of bleaching, the decomposition rate of $\mathrm{H}_{2} \mathrm{O}_{2}$ descended or even no longer decomposed effectively, which made it more difficult to improve the WI of cotton fabrics. The results implied that cotton fabric bleaching in $\mathrm{H}_{2} \mathrm{O}_{2} / \mathrm{GT}$ system could achieve satisfactory $\mathrm{WI}$ in a short time. Hence, the bleaching time was selected at $60 \mathrm{~min}$ in $\mathrm{H}_{2} \mathrm{O}_{2} / \mathrm{GT}$ system to save energy. It is recommended that the productivity can be improved by shortening the bleaching time if the bleached cotton knitted fabric is to be dyed in a dark color.

\subsection{Comparison of $\mathrm{H}_{2} \mathrm{O}_{2} / \mathrm{GT}$ system and $\mathrm{H}_{2} \mathrm{O}_{2}$ /TAED svstem in cotton bleaching \\ Loading [MathJax]/jax/output/CommonHTML/jax.js}


As displayed in Table. 1, the performance of GT as the activator in cotton knitted fabrics bleaching was compared to that of TAED. Both TAED and GT could be the activators in low temperature bleaching system since the WI of cotton fabrics was palpably improved with little damage to bursting strength. Compared to the $\mathrm{H}_{2} \mathrm{O}_{2}$ system without activators, GT and TAED could activate $\mathrm{H}_{2} \mathrm{O}_{2}$ to bleach cotton knitted fabrics at low temperature with 20.2 and 24.83 degrees increase of $\mathrm{WI}$, and $1.21 \%$ and $8.41 \%$ loss of rate in bursting strength respectively. The comparing result showed that the bleaching performance of $\mathrm{H}_{2} \mathrm{O}_{2}$ /GT system was analogous to $\mathrm{H}_{2} \mathrm{O}_{2}$ /TAED system. However, GT has its own advantages as a bleaching activator. One is that GT can be obtained from a wide range of sources without synthesis and the price of GT is much lower than TAED. The other is that compared with TAED, GT has better water solubility. Hence, GT has a good application prospect as an activator to bleach cotton fabrics at low temperature in the textile industry.

\section{Table 1}

Comparison of bleaching performance between $\mathrm{H}_{2} \mathrm{O}_{2} / \mathrm{GT}$ system and $\mathrm{H}_{2} \mathrm{O}_{2}$ /TAED system.

\begin{tabular}{|c|c|c|c|c|c|}
\hline $\begin{array}{l}\text { Bleaching } \\
\text { method }\end{array}$ & $\mathrm{pH}$ & $\begin{array}{l}\text { Bleaching activators } \\
(\mathrm{mmol} / \mathrm{L})\end{array}$ & $\begin{array}{l}30 \% \mathrm{H}_{2} \mathrm{O}_{2} \\
(\mathrm{mmol} / \mathrm{L})\end{array}$ & WI (\%) & $\begin{array}{l}\text { Bursting } \\
\text { strength }(\mathrm{N})\end{array}$ \\
\hline Unbleached & - & - & - & -3.31 & $1070.05 \pm 70.62$ \\
\hline $\mathrm{H}_{2} \mathrm{O}_{2}$ & 9 & - & 60 & $\begin{array}{l}52.09 \pm \\
1.05\end{array}$ & $979.47 \pm 47.64$ \\
\hline $\mathrm{H}_{2} \mathrm{O}_{2} /$ TAED & 9 & 25 & 60 & $\begin{array}{l}76.92 \pm \\
0.5\end{array}$ & $980 \pm 53.11$ \\
\hline $\mathrm{H}_{2} \mathrm{O}_{2} / \mathrm{GT}$ & 9 & 25 & 60 & $\begin{array}{l}72.29 \pm \\
1.14\end{array}$ & $1057.67 \pm 63.58$ \\
\hline
\end{tabular}

\subsection{Mechanism of $\mathrm{H}_{2} \mathrm{O}_{2} / \mathrm{GT}$ bleaching for cotton}

It has been demonstrated that hydroxyl radicals play a significant role in activated peroxide bleaching system at lower temperature by using benzenepentacarboxylic acid (BA) as a fluorescent probe of hydroxyl radicals ( $\mathrm{Si}$ et al. 2014). In these bleaching systems, $\mathrm{H}_{2} \mathrm{O}_{2}$ could be activated to produce peracids at low temperature by adding bleaching activators, and then the generated peracids could significantly promote the generation of hydroxyl radicals resulting in a prominent increase in fluorescence intensity (Li et al. 2020; Liu et al. 2018; Si et al. 2014a). Therefore, the bleaching process and mechanism of the $\mathrm{H}_{2} \mathrm{O}_{2}$ /GT system was investigated by BA.

Compared to $\mathrm{H}_{2} \mathrm{O}_{2}$ system without activators, $\mathrm{GT}$ could markedly increase the generation of $\mathrm{HO}$. under the same alkaline conditions, and the fluorescence intensity was enhanced by nearly 4 times at $60^{\circ} \mathrm{C}$ for 60 minutes (Fig. 6). This can be interpreted that GT could react with $\mathrm{HOO}^{-}$decomposed by $\mathrm{H}_{2} \mathrm{O}_{2}$ under 
alkaline conditions to form peracetic acids, which consequently promoted the decomposition of $\mathrm{H}_{2} \mathrm{O}_{2}$ and the generation of HO. (Si et al. 2014a).

The WI of cotton fabrics treated with dimethyl sulfoxide (DMSO) as a $\mathrm{HO}$. scavenger was evaluated to further elucidate the bleaching effect of $\mathrm{HO}$ (Fig. 7). Compared $\mathrm{H}_{2} \mathrm{O}_{2} / \mathrm{GT}$ bleaching system $\left(60^{\circ} \mathrm{C}\right)$ with $\mathrm{H}_{2} \mathrm{O}_{2}$ bleaching system $\left(98^{\circ} \mathrm{C}\right)$, both two systems could adjust the concentration of $\mathrm{HO} \cdot$ by adding different concentration of DMSO. In general, the WI of the cotton fabrics in the two systems decreased with the addition of DMSO. With the concentration of DMSO increased from 0 to $4 \mathrm{~g} / \mathrm{L}$, the WI of $\mathrm{H}_{2} \mathrm{O}_{2}$ bleached cotton fabric fell by 4.45 , while for the $\mathrm{H}_{2} \mathrm{O}_{2}$ / $\mathrm{GT}$ bleaching system, the WI dramatically decreased by 23.83 . The results above demonstrated that $\mathrm{HO}$. could make important contributions to the WI of bleached cotton fabric. However, $\mathrm{HO}$. had slightly effects on WI of $\mathrm{H}_{2} \mathrm{O}_{2}$ bleached cotton fabric due to its lower $\mathrm{HO}$. concentration. On the other hand, it was proved that other effective constituents except $\mathrm{HO}$; such as $\mathrm{HOO}^{-}$contributed to the high WI of cotton samples bleached in $\mathrm{H}_{2} \mathrm{O}_{2}$ system. While in $\mathrm{H}_{2} \mathrm{O}_{2} / \mathrm{GT}$ bleaching system, the bleach activator $\mathrm{GT}$ could promote the generation of PAA and $\mathrm{HO} \cdot$ to bleach cotton fabric at lower temperature, which means that not only PAA but also HO could play a significant role in $\mathrm{H}_{2} \mathrm{O}_{2}$ /GT bleaching system.

GT has three ester carbonyls and it is uncertain whether higher amounts of the ester carbonyl groups could produce higher concentration of PAA, and then promote the bleaching of cotton knitted fabrics. Based on this fact, Monoacetin and Diacetin were respectively added into the $\mathrm{H}_{2} \mathrm{O}_{2}$ bleaching system to confirm that more peroxyacetic acid could be formed using GT as an activator. Then the bleaching performances of $\mathrm{H}_{2} \mathrm{O}_{2}$ /Diacetin and $\mathrm{H}_{2} \mathrm{O}_{2}$ /Monoacetin systems were discussed by comparing with $\mathrm{H}_{2} \mathrm{O}_{2}$ system without activators. As shown in Fig. 8, the addition of Diacetin and Monoacetin could increase the WI of cotton fabrics, but not as much as that of GT. This confirms that the greater the content of ester carbonyl groups, the more favorable the production of peroxyacid and the bleaching of cotton fabrics.

According to the results above, PAA was produced by the perhydrolysis reaction in $\mathrm{H}_{2} \mathrm{O}_{2}$ /GT bleaching system due to the nucleophilic attack of $\mathrm{HOO}^{-}$to GT. Meanwhile, GT may undergo hydrolysis under alkaline condition, which was ineffective for bleaching cotton knitted fabrics. As shown in scheme 1, the produced PAA could directly act in the bleaching of cotton knitted fabrics. At the same time, PAA may undergo three kinds of decomposition, which includes the nucleophilic attack by $\mathrm{HOO}^{-}$, spontaneous decomposition and decomposition of PAA into other active substances (such as $\mathrm{HO} \cdot$ ) under alkaline conditions. In $\mathrm{H}_{2} \mathrm{O}_{2}$ /GT system, not only PAA but also $\mathrm{HO}$. and other active materials generated from the decomposition of peracetic acid play an important role in improving the WI of cotton fabrics.

\section{Conclusion}

In this work, GT was utilized as an activator of hydrogen peroxide to bleach cotton knitted fabrics at lower temperature to save energy. The performance and mechanism of $\mathrm{H}_{2} \mathrm{O}_{2} / \mathrm{GT}$ system in cotton fabrics bleaching were discussed. By addition of GT, the WI of scoured cotton knitted fabrics (24.47) increased to Loading [MathJax]/jax/output/CommonHTML/jax.js ainably increased to $52 \%$ at $60{ }^{\circ} \mathrm{C}$. The temperature and $\mathrm{pH}$ 
value could also affect the bleaching performance of the $\mathrm{H}_{2} \mathrm{O}_{2} / \mathrm{GT}$ system. By using BA as a fluorescent probe to capture $\mathrm{HO}$, it was found that the amount of $\mathrm{HO}$. generated in $\mathrm{H}_{2} \mathrm{O}_{2}$ /GT system was nearly 4 times greater than that of the $\mathrm{H}_{2} \mathrm{O}_{2}$ system without GT. DMSO as a scavenger of $\mathrm{HO}$ - proved that $\mathrm{HO}$. was also one of the important ingredients affecting the bleaching performance in $\mathrm{H}_{2} \mathrm{O}_{2} / \mathrm{GT}$ system. The bleaching mechanism of $\mathrm{H}_{2} \mathrm{O}_{2} / \mathrm{GT}$ system was proposed. On the one hand, PAA produced by perhydrolysis reaction bleached impurities in cotton knitted fabrics directly. On the other hand, $\mathrm{HO}$. and other active materials generated from the decomposition of PAA then removed impurities and enhance the WI of $\mathrm{H}_{2} \mathrm{O}_{2} / \mathrm{GT}$ system. The use of $\mathrm{GT}$ as an activator of hydrogen peroxide may provide an effectivecost and eco-friendly alternative approach for bleaching cotton knitted fabrics under mild conditions.

\section{Declarations}

\section{Acknowledgements}

This work was financially supported by the National Key R\&D Program of China (2017YFB0309200), Fundamental Research Funds for the Central Universities (JUSRP51717A) and International Joint Research Laboratory for Eco- Textile Technology at Jiangnan University.

\section{Conflict of interest}

The authors declare no competing financial interest.

This article does not contain any studies with human participants or animals performed by any of the authors.

Informed consent was obtained from all individual participants included in the study.

\section{References}

Abdel-Halim ES, Al-Deyab SS(2011)Low temperature bleaching of cotton cellulose using peracetic acid. Carbohydr Polym 86(2):988-994. https://doi.org/10.1016/j.carbpol.2011.05.051

Abdel-Halim ES, Al-Deyab SS(2013)One-step bleaching process for cotton fabrics using activated hydrogen peroxide. Carbohydr Polym 92(2):1844-1849. http://dx.doi.org/10.1016/j.carbpol.2012.11.045

Bashar MM, Siddiquee MAB, Khan MA(2015)Preparation of cotton knitted fabric by gamma radiation: A new approach. Carbohydr Polym 120:92-101. https://doi.org/10.1016/j.carbpol.2014.11.023

Bianchetti GO, Devlin CL, Seddon KR(2015)Bleaching systems in domestic laundry detergents: a review. Rsc Adv 5(80):65365-65384. https://doi.org/10.1039/c5ra05328e

Cai JY, Evans DJ, Smith SM(2001)Bleaching of with TAED and NOBS activated peroxide systems. AATCC 
Chen W, Wang L, Wang D, Zhang J, Sun C, Xu C(2016)Recognizing a limitation of the TBLC-activated peroxide system on low-temperature cotton bleaching. Carbohydr Polym 140:1-5.

http://dx.doi.org/10.1016/j.carbpol.2015.12.013

Fei X, Yao J, Du J, Sun C., Xiang Z, Xu C(2015)Analysis of factors affecting the performance of activated peroxide systems on bleaching of cotton fabric. Cellulose 22(2):1379-1388.

https://doi.org/10.1007/s10570-015-0550-1

Hashem M, El-Bisi M, Sharaf S, Refaie R(2010)Pre-cationization of cotton fabrics: An effective alternative tool for activation of hydrogen peroxide bleaching process. Carbohydr Polym 79(3):533-540. https://doi.org/10.1016/j.carbpol.2009.08.038

Hebeish A, Hashem M, Shaker N, Ramadan M, El-Sadek B, Hady MA(2009)New development for combined bioscouring and bleaching of cotton-based fabrics. Carbohydr Polym 78(4):961-972. https://doi.org/10.1016/j.carbpol.2009.07.019

Hofmann JR, Just G, Pritzkow W, Schmidt H(1992)Bleaching Activators and the mechanism of bleaching activation. J Prak Chem Chem Ztg 334(4):293-297. http://dx.doi.org/10.1002/prac.19923340402

Lee, JJ, Hinks D, Lim SH, Hauser P(2010)Hydrolytic stability of a series of lactam-based cationic bleach activators and their impact on cellulose peroxide bleaching. Cellulose 17(3):671-678. https://doi.org/ $\underline{10.1007 / \mathrm{s} 10570-009-9390-1}$

Li Q, Ni L, Wang J, Quan H, Zhou Y(2020)Establishing an ultrasound-assisted activated peroxide system for efficient and sustainable scouring-bleaching of cotton/spandex fabric. Ultrasonics Sonochemistry 68C:105220. https://doi.org/10.1016/j.ultsonch.2020.105220

Lim SH, Lee JJ, Hinks D, Hauser P(2006)Bleaching of cotton with activated peroxide systems. Coloration Technology 121(2):89-95. http://dx.doi.org/10.1111/j.1478-4408.2005.tb00258.x

Liu K, Zhang X, Yan K(2017)Low-temperature bleaching of cotton knitting fabric with $\mathrm{H}_{2} \mathrm{O}_{2}$ /PAG system. Cellulose 24(3):1555-1561. http://dx.doi.org/10.1007/s10570-016-1167-8

Liu K, Zhang X, Yan K(2018)Bleaching of cotton fabric with tetraacetylhydrazine as bleach activator for $\mathrm{H}_{2} \mathrm{O}_{2}$. Carbohydr Polym 188:221-227. https://doi.org/10.1016/j.carbpol.2018.01.111

Long X, Xu C, Du J, Fu S(2013)The TAED $/ \mathrm{H}_{2} \mathrm{O}_{2} / \mathrm{NaHCO} 3$ system as an approach to low-temperature and near-neutral pH bleaching of cotton. Carbohydr Polym 95(1):107-113.

https://doi.org/10.1016/j.carbpol.2013.02.061

Luo X, Shao D, Xu C, Wang Q, Gao W(2019)An eco-friendly way to whiten yellowish anti-wrinkle cotton fabrics using TBCC-activated peroxide low-temperature post-bleaching. Cellulose 26(5):3575-3588. httos://doi.ora/10.1007/s10570-019-02316-0

Loading [MathJax]/jax/output/CommonHTML/jax.js

Page $11 / 21$ 
Neal JM(1998)Oxygen bleaching systems in domestic laundry. J Surfactants Deterg 1(2):253-261. https://doi.org/10.1007/s11743-998-0029-z

Shao J, Huang Y, Wang Z, Liu J(2010)Cold pad-batch bleaching of cotton fabrics with a TAED $/ \mathrm{H}_{2} \mathrm{O}_{2}$ activating system. Coloration Technology 126(2):103-108. https://doi.org/10.1111/j.14784408.2010.00234.x

Si F, Yan $\mathrm{K}$, Zhang $\mathrm{X}(2014 \mathrm{a})$ Study on $\mathrm{H}_{2} \mathrm{O}_{2}$ /TAED and $\mathrm{H}_{2} \mathrm{O}_{2}$ /TBCC bleaching mechanism related to hydroxyl radical with a fluorescent probe. Carbohydr Polym 103:581-586.

http://dx.doi.org/10.1016/j.carbpol.2013.12.052

Si F, Zhang X, Yan K(2014b)The quantitative detection of HO center dot generated in a high temperature $\mathrm{H}_{2} \mathrm{O}_{2}$ bleaching system with a novel fluorescent probe benzenepentacarboxylic acid. Rsc Adv 4(12):58605866. https://doi.org/10.1039/c3ra45975f

Sun D, Stylios GK(2004)Effect of low temperature plasma treatment on the scouring and dyeing of natural fabrics. Textile Research Journal 74(9):751-756. https://doi.org/10.1177/004051750407400901

Wakelyn PJ, Bertoniere NR, French AD, Thibodeaux DP, Triplett BA, Rousselle MA, Goynes WR, Edwards JV, Hunter L, Mcalister DD(2007)Chemical Composition of Cotton in, Cotton Fiber Chemistry and Technology p 15. https://doi.org/10.1201/9781420045888

Xu C, Long X, Du J, Fu S(2013)A critical reinvestigation of the TAED-activated peroxide system for lowtemperature bleaching of cotton. Carbohydr Polym 92(1):249-253.

http://dx.doi.org/10.1016/j.carbpol.2012.08.088

Xu C, Hinks D, Sun C, Wei Q(2015)Establishment of an activated peroxide system for low-temperature cotton bleaching using N-4-(triethylammoniomethyl)benzoyl butyrolactam chloride. Carbohydr Polym 119:71-77. http://dx.doi.org/10.1016/j.carbpol.2014.11.054

Zeronian SH, Inglesby MK(1995)Bleaching of cellulose by hydrogen peroxide. Cellulose 2(4):265-272. http://dx.doi.org/10.1007/BF00811817

\section{Figures}




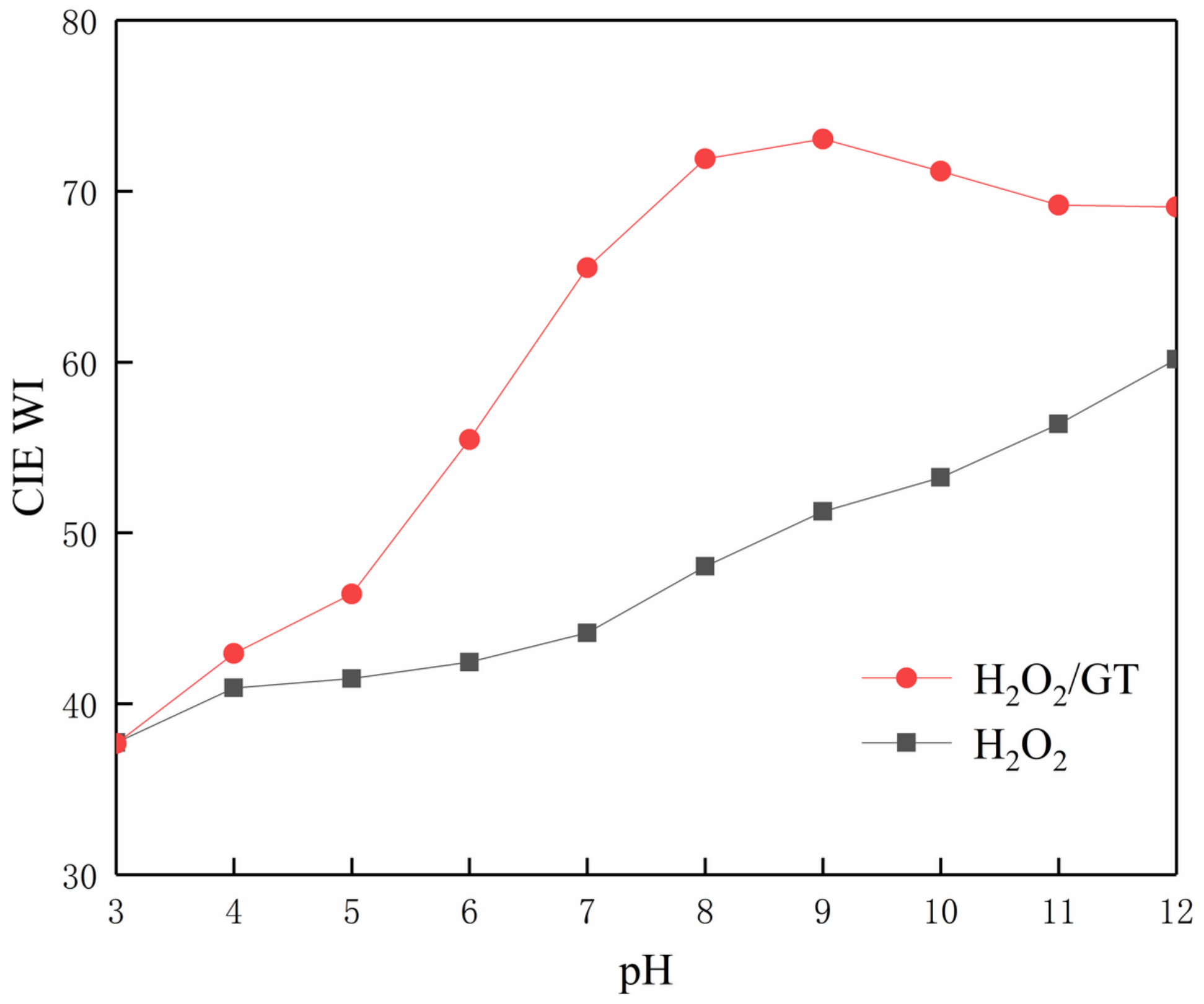

Figure 1

Effect of $\mathrm{pH}$ on Wl of cotton fabric. Bleaching condition: $60^{\circ} \mathrm{C} ; 60 \mathrm{~min}, \mathrm{H} 2 \mathrm{O} 2(80 \mathrm{mmol} / \mathrm{L}), \mathrm{GT}(8 \mathrm{~g} / \mathrm{L})$, $\mathrm{Na} 4 \mathrm{P} 2 \mathrm{O} 7(2 \mathrm{~g} / \mathrm{L})$. 
(a)
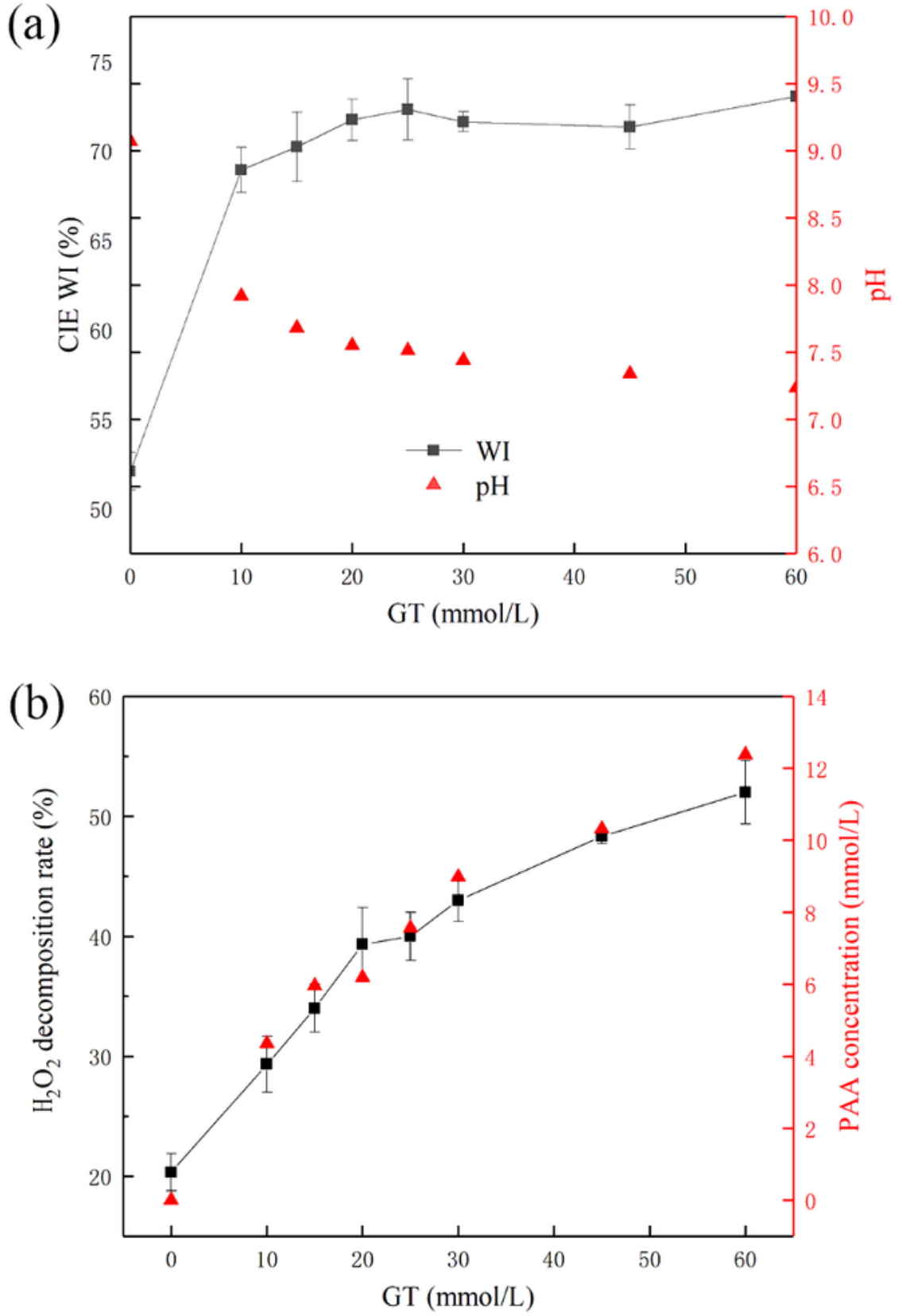

Figure 2

Effect of GT concentration on WI, $\mathrm{pH}, \mathrm{H} 2 \mathrm{O} 2$ decomposition rate and PAA concentration in H2O2/GT bleaching system: (a) $\mathrm{WI}$ and $\mathrm{pH}$; (b) $\mathrm{H} 2 \mathrm{O} 2$ decomposition rate and PAA concentration. $\mathrm{pH} 9 ; 60{ }^{\circ} \mathrm{C} ; 60$ min; 30\% H2O2 (60 mmol/L); Na4P2O7 (2 g/L). 


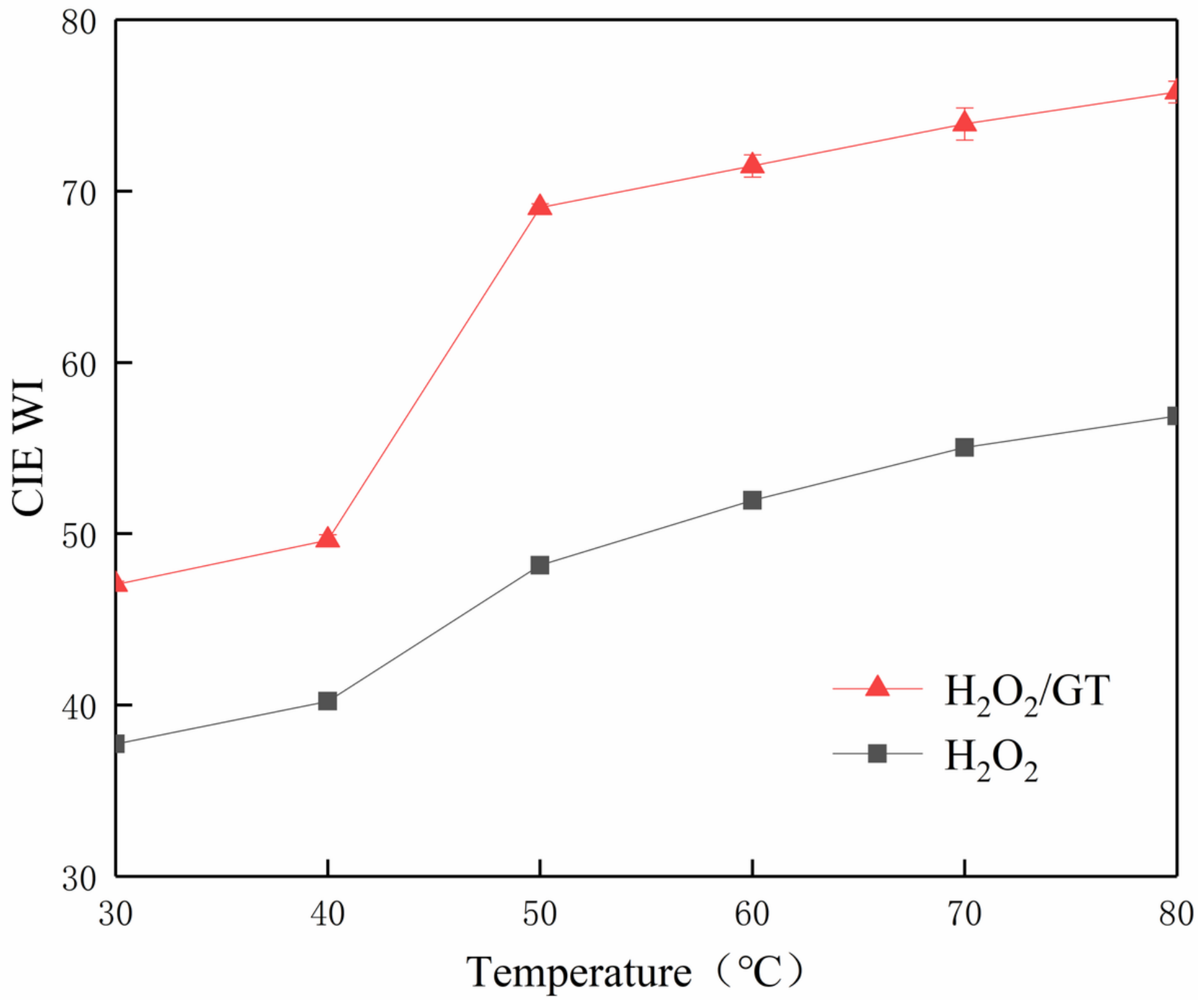

Figure 3

Effect of Temperature on WI in H2O2/GT bleaching system. pH 9; 60 min; 30\% H2O2 (60 mmol/L; GT (25 $\mathrm{mmol} / \mathrm{L}) ; \mathrm{Na} 4 \mathrm{P} 2 \mathrm{O} 7$ (2 g/L). 


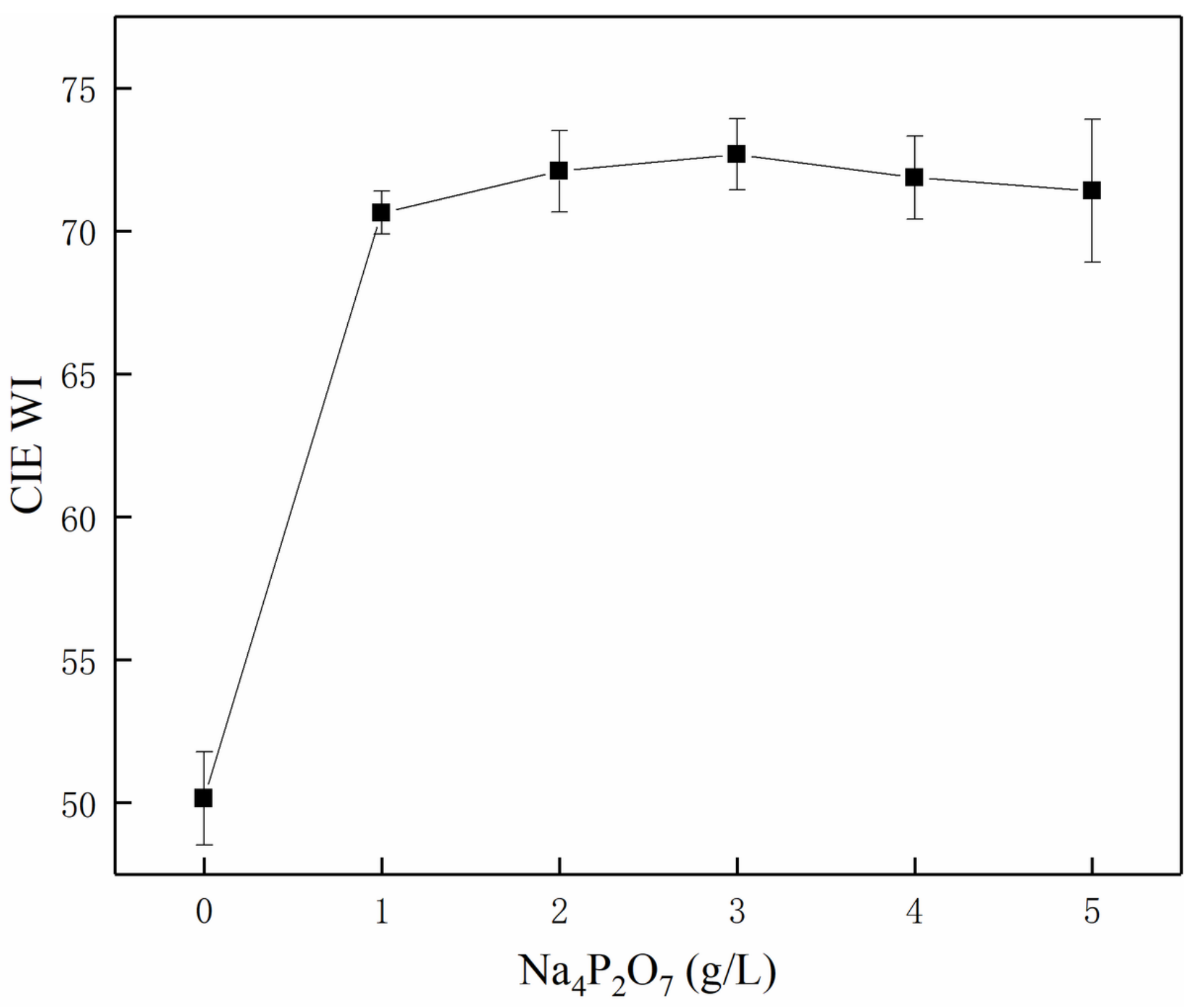

Figure 4

Effect of Stabilizer concentration on WI in H2O2/GT bleaching system. pH 9; $60{ }^{\circ} \mathrm{C} ; 60$ min; $30 \% \mathrm{H} 2 \mathrm{O} 2$ (60 mmol/L); GT (25 mmol/L). 


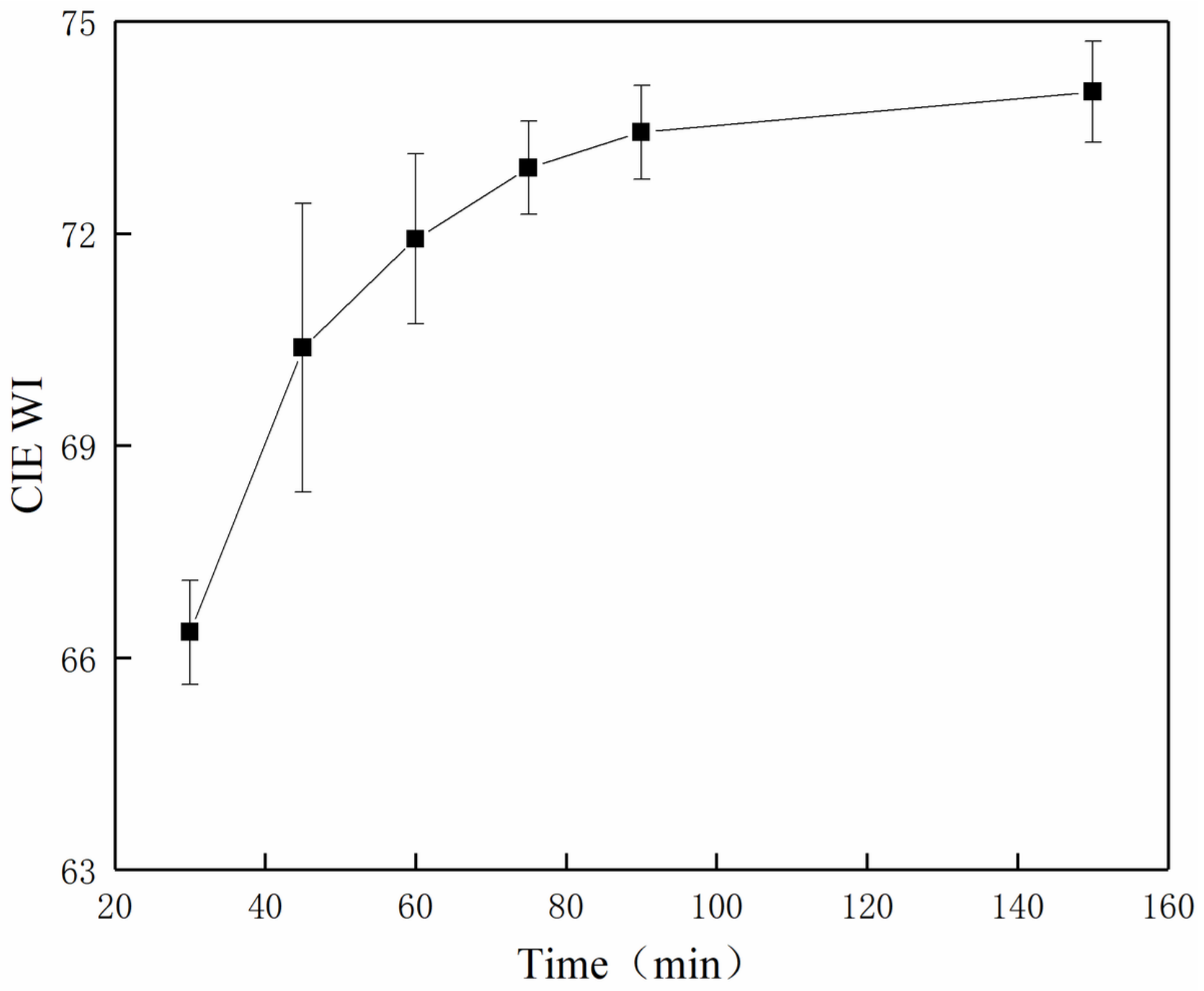

Figure 5

Effect of Bleaching time on $\mathrm{Wl}$ in $\mathrm{H} 2 \mathrm{O} 2 / \mathrm{GT}$ bleaching system. $\mathrm{pH} 9 ; 60{ }^{\circ} \mathrm{C} ; 30 \% \mathrm{H} 2 \mathrm{O} 2(60 \mathrm{mmol} / \mathrm{L})$; GT (25 mmol/L); Na4P2O7 (2 g/L). 


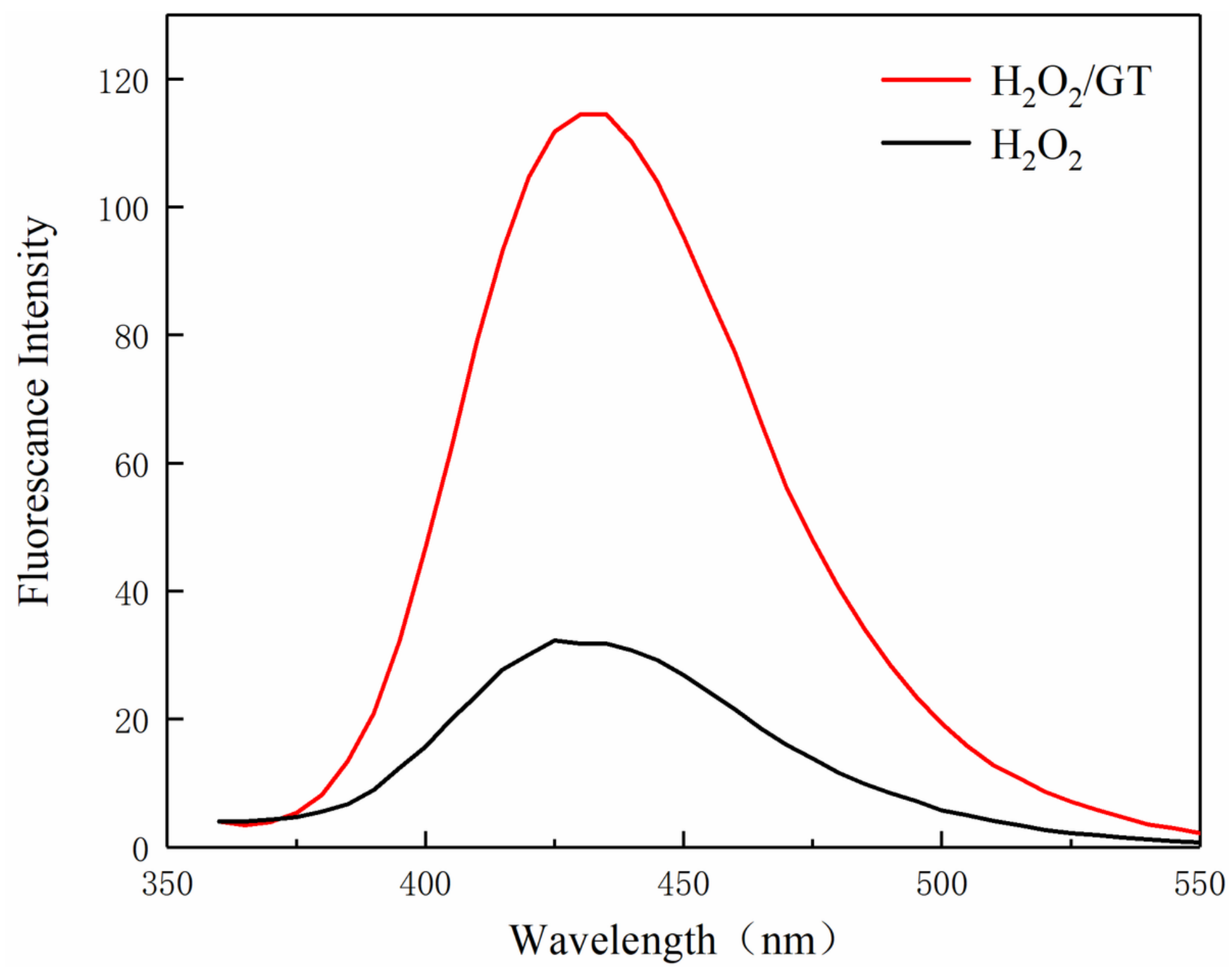

Figure 6

HO genneration in $\mathrm{H} 2 \mathrm{O} 2 / \mathrm{GT}$ system and $\mathrm{H} 2 \mathrm{O} 2$ system without activator at $60{ }^{\circ} \mathrm{C}$ for 60 min. 


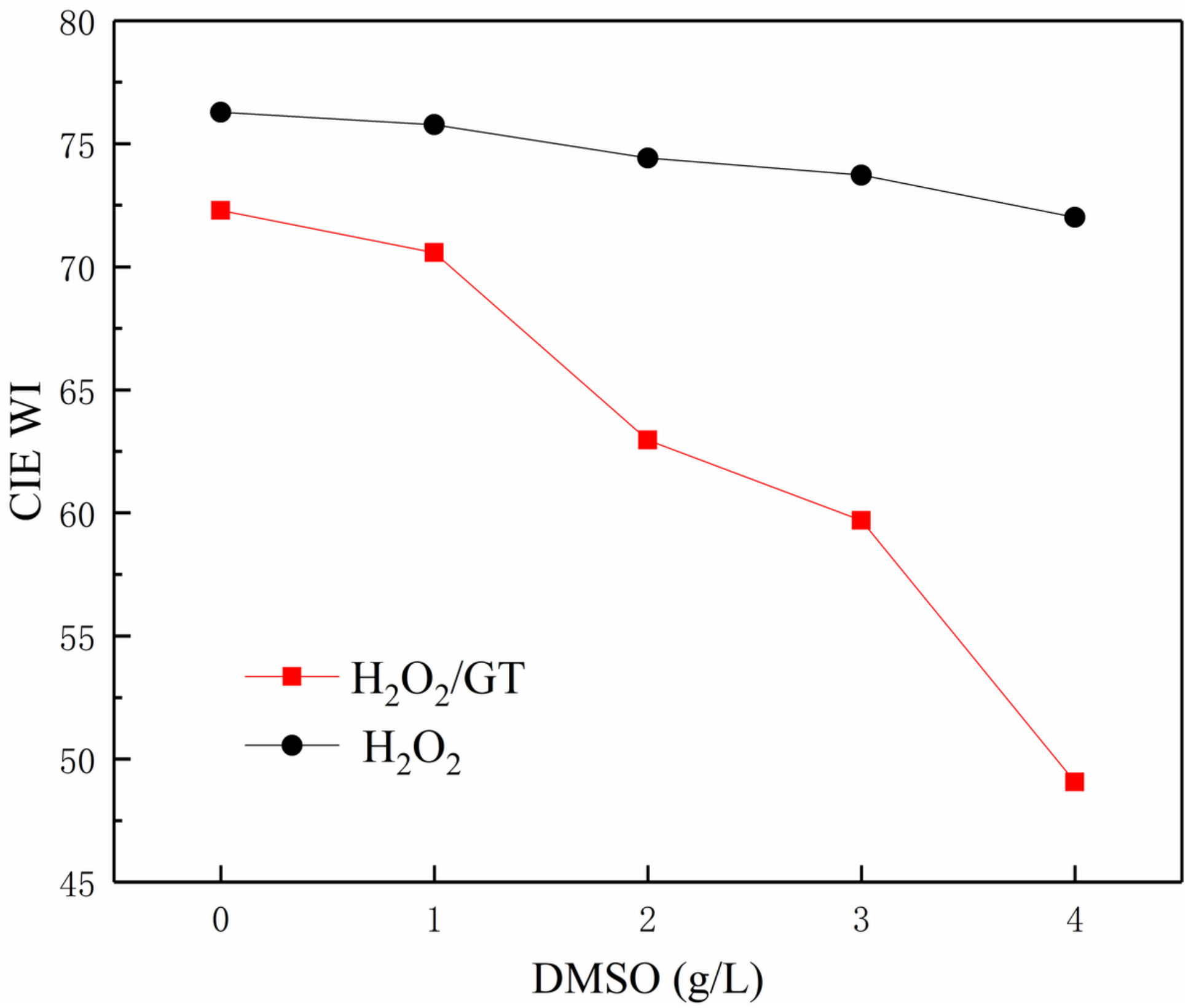

Figure 7

Effect of DMSO on WI in H2O2/GT bleaching system and H2O2 bleaching system. H2O2/GT system: 60 ${ }^{\circ} \mathrm{C} ; \mathrm{pH}$ 9; $60 \mathrm{~min} ; 30 \% \mathrm{H} 2 \mathrm{O} 2$ (60 mmol/L); GT (25 mmol/L); Na4P2O7 (2 g/L); H2O2 system: $100^{\circ} \mathrm{C} ; \mathrm{pH}$ $11 ; 60$ min; 30\% H2O2 (8 g/L); $\mathrm{NaOH}(1 \mathrm{~g} / \mathrm{L}) ; \mathrm{NaSiO} 3(3 \mathrm{~g} / \mathrm{L})$. 


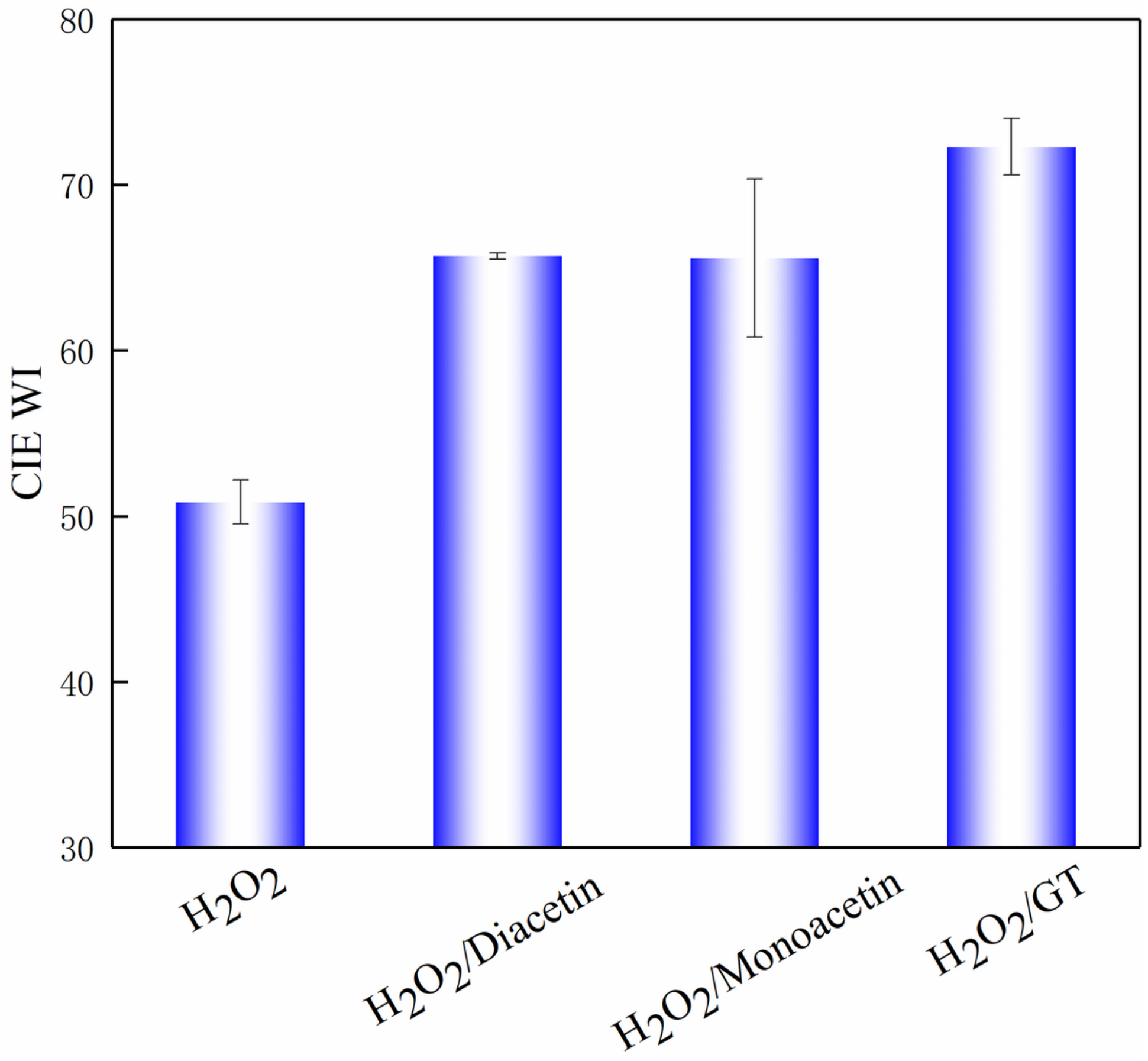

Figure 8

Bleaching performance of different systems. $60{ }^{\circ} \mathrm{C} ; \mathrm{pH}$ 9; $60 \mathrm{~min} ; 30 \% \mathrm{H} 2 \mathrm{O} 2$ (60 mmol/L); Na4P2O7 (2 $\mathrm{g} / \mathrm{L})$; Diacetin (25 mmol/L); Monoacetin ( $25 \mathrm{mmol} / \mathrm{L})$.

\section{Supplementary Files}

This is a list of supplementary files associated with this preprint. Click to download. 
Page 21/21 